\title{
ALCOÓLICOS ANÔNIMOS E A RECAÍDA: ANÁLISE À LUZ DA EXPERIÊNCIA ELEMENTAR
}

\author{
ALCOHOLICS ANONYMOUS AND RELAPSE: ANALYSIS IN THE LIGHT OF THE ELEMENTAL \\ EXPERIENCE
}

ALCOHÓLICOS ANÓNIMOS Y LA RECAÍDA: ANÁLISIS A LA LUZ DE LA EXPERIENCIA
ELEMENTAL

Dionete Maria Mendes Nogueira* Achilles Gonçalves Coelho Júnior **

\begin{abstract}
RESUMO
A recaída é considerada, em alguns estudos, como um processo que compreende tanto o retorno ao consumo da substância química como os momentos anteriores que advertem sobre o risco de o abstêmio recidivar. $\mathrm{O}$ programa dos Alcoólicos Anônimos (AA) visa à sobriedade pela abstinência total do álcool. O objetivo da pesquisa foi analisar a expressão da experiência elementar no processo de recaída vivenciado por membro de AA, com base na elaboração da experiência dos sujeitos. Trata-se de pesquisa qualitativa, cuja coleta de dados deu-se mediante entrevistas semiestruturadas, das quais participaram cinco membros de AA de três grupos de Montes Claros-MG. Empregou-se a análise fenomenológica para o tratamento dos dados, via que possibilitou a apreensão de quatro categorias temáticas: pertencimento; posicionamento pessoal; exigência de ser; e experiência religiosa. A dinâmica da experiência elementar do alcoolista, expressa no processo de recaída, orienta o posicionamento deste diante de si e do mundo.
\end{abstract}

Palavras-chave: Alcoólicos Anônimos. Recaída. Experiência elementar. Fenomenologia.

\begin{abstract}
Relapse is considered in some studies as a process which comprises both the return to the use of a chemical substance as well as the previous moments warning about the danger of an abstemious person to relapse. The Alcoholics Anonymous Program (AA) aims to reach sobriety based on total alcohol abstinence. The objective of the research was to analyze the expression of elemental experience in the process of relapse experienced by
\end{abstract}

\footnotetext{
Texto recebido em 11 de maio de 2015 e aprovado para publicação em 14 de junho de 2016.

*Acadêmica de Psicologia, bolsista do Programa de Iniciação Científica das Faculdades Integradas Pitágoras de Montes Claros-MG, Brasil.E-mail: dionete_mendes@yahoo.com.br.

**Doutorando pela FFCLRP da Universidade de São Paulo (USP), mestre em Psicologia Social pela Universidade Federal de Minas Gerais e professor e coordenador do Serviço de Atendimento Psicopedagógico das Faculdades Integradas Pitágoras de Montes Claros-MG. E-mail: achillescoelho@yahoo.com.br.
} 
AA members, through the elaboration of the subjects' experiences. It turns out to be a qualitative research, where the data collection procedure occurred through semi-structured interviews. The interviewees were five members from three AA groups in the city of Montes Claros-MG. We applied the phenomenological analysis to process the data, which allowed us to establish four thematic categories: belonging; personal positioning; requirement for being; and religious experience. The dynamics of the alcoholics' elementary experience, expressed in the relapse process is the guide to their attitudes towards themselves and the world.

Keywords: Alcoholics Anonymous. Relapse. Elemental experience. Phenomenology.

\section{RESUMEN}

La recaída es considerada en algunos estudios como un proceso que incluye tanto el hecho de volver a consumir sustancias químicas, como los momentos anteriores que advierten del riesgo de que el abstemio reincida. El programa de Alcohólicos Anónimos (AA) tiene como objetivo la sobriedad a través de abstinencia total de alcohol. El objetivo de la investigación fue analizar la expresión de la experiencia elemental en el proceso de recaída experimentada por miembros de AA con base en la elaboración de la experiencia de los sujetos. Se trata de una investigación cualitativa, cuya recolección de datos se dio a través de entrevistas semiestructuradas, en las cuales participaron cinco miembros de AA de tres grupos de Montes Claros-MG. Se aplicó el análisis fenomenológico para tratamiento de datos, lo que permitió captar cuatro categorías temáticas: pertenecimiento; posicionamiento personal; exigencia de ser; y experiencia religiosa. La dinámica de la experiencia elemental del alcohólico, expresada en el proceso de recaída, indica su posicionamiento ante sí mismo y el mundo.

Palabras clave: Alcohólicos Anónimos. Recaída. Experiencia elemental. Fenomenología.

\section{INTRODUÇÃO}

O alcoolismo já representa uma das maiores preocupações de saúde pública no Brasil, e altas taxas de suicídios e recaídas têm sido associadas à comorbidade relativa a transtornos relacionados ao consumo de álcool com outras doenças psiquiátricas. ${ }^{1}$ Vários autores têm discutido essa problemática visando tanto a esclarecer os fatores de riscos fisiológicos, comportamentais e sociais ligados a essa questão como a estabelecer formas de tratamento eficazes

\footnotetext{
Artigo elaborado com base na pesquisa desenvolvida nas Faculdades Integradas Pitágoras de Montes Claros-MG, com bolsa de iniciação científica, tendo sido apresentada comunicação oral referente no I Congresso Internacional Pessoa e Comunidade: Fenomenologia, Psicologia e Teologia e III Colóquio Internacional de Humanidades e Humanização da Saúde, realizado na Universidade de São Paulo (USP), em 2014.
} 
para o alcoolismo (Álvarez, 2007; França \& Siqueira, 2011; Rigotto \& Gomes, 2002).

A Psicologia tem participado das discussões, na interface com a saúde pública, acerca de maneiras de compreensão e manejo com o usuário de álcool e outras drogas, e tem contribuído para o debate de questóes fundamentais relativas ao alcoolismo, como a responsabilidade do indivíduo e sua liberdade de escolha, buscando a abertura de espaço para discussão, reflexão e análise crítica sobre essa problemática, principalmente, a partir da política de redução de danos, política de assistência social na atenção aos usuários de álcool e outras drogas e maneiras de pensar o uso das drogas na contemporaneidade (Conselho Federal de Psicologia, 2013; Passos \& Souza, 2011).

Os Alcoólicos Anônimos (AA), que consideram o alcoolismo como uma doença incurável e progressiva, denominam-se como uma irmandade de homens e mulheres voluntários, que compartilham suas experiências, forças e esperanças, tendo por objetivo alcançar a sobriedade pela abstinência total do álcool (Alcoólicos Anônimos, 2008, 2011; Pires \& Schneider, 2013). Na luta cotidiana para manterem-se abstêmios, os membros de AA relatam passar pela experiência da recaída, a qual é definida, em alguns estudos, como um processo, que compreende não só o retorno real ao uso de uma substância psicoativa, mas, e inclusive, os momentos anteriores marcados por indícios que advertem sobre o perigo de uma recidiva. Rigotto e Gomes (2002) explicam que a recaída faz parte do processo de mudança que o alcoolista empreende, e Álvarez (2007) expõe que a recidiva pode contribuir para que o alcoolista possa aprender com a experiência e recomece um processo de reabilitação de maneira mais consciente.

Assim, tomamos a definição de recaída como um processo caracterizado por três momentos que se correlacionam: os momentos anteriores ao ato concreto do abstêmio retornar ao consumo de bebidas alcoólicas, à volta real ao uso do álcool e os momentos posteriores a esse retorno. Torna-se evidente, portanto, que momentos da própria abstinência devem ser avaliados dentro do contexto do processo de recaída e atentar para esses três momentos que integram esse processo possibilita a apreensão da experiência vivenciada pelo alcoolista, no seu processo de recaída, em sua inteireza.

A proposta da experiência elementar, trazida por Giussani (2009), aliada às contribuiçōes da Fenomenologia, revela-se fundamental para a Psicologia, por considerar a unidade do eu e a dinâmica própria da experiência humana, pois, segundo explicam Gaspar e Mahfoud (2006), torna-se "essencial em qualquer intervenção psicológica respeitar e compreender o ser do outro, facilitando o surgimento de uma dinâmica que se revela na comparação das vivências com 
as exigências que traz consigo" (p. 8). Nesses termos, buscou-se, por meio deste estudo, analisar a expressão da experiência elementar no processo de recaída vivenciado por membro de AA, a partir da elaboração da experiência dos sujeitos.

A experiência elementar, segundo Giussani (2009) designa "um conjunto de exigências e evidências com as quais o homem é lançado no confronto com tudo o que existe" (p. 24), tratando-se, portanto, daquele "ímpeto original com o qual o ser humano se lança na realidade procurando identificar-se com ela por meio da realização de um projeto que imprima à própria realidade a imagem ideal que o estimula interiormente" (p. 27). Assim, Mahfoud (2012) enfatiza que a experiência elementar está na base de todo gesto ou posicionamento humano, pelo qual o sujeito tanto pode reconhecer seus anseios fundamentais como as exigências de felicidade, de justiça, de beleza como reconhecer evidências, também, fundamentais, tais como a existência e a realidade que transcende a ela.

\section{MÉTODO}

Trata-se de pesquisa qualitativa ${ }^{2}$ conduzida pelo método fenomenológico. Nas pesquisas que usam como método de investigação a Fenomenologia, buscase permitir a revelação da experiência para conhecê-la, e esse conhecimento não é definido de maneira prévia, mas pela manifestação do fenômeno experienciado. Assim, um pequeno número de sujeitos típicos pode sustentar uma delimitação suficiente, vez que a investigação busca alcançar aspectos que estejam relacionados com as vivências dos sujeitos (Barreira \& Ranieri, 2013). Nesses termos, empregamos a amostragem não probabilística por tipicidade ou intencional (Gil, 2008), que possibilitou a seleção de cinco membros de AA de três grupos de Montes Claros-MG, os quais foram identificados de "E1" a "E5.

Usamos um roteiro de entrevista que teve por objetivo o levantamento sobre o tempo de consumo de álcool pelo alcoolista, o tempo em que este se encontrava em abstinência e o número de recaídas em que incorreu. Entretanto esse roteiro não visava a levantamentos quantitativos nem significou rigidez na condução das entrevistas, visto que os participantes, sem se prenderem a perguntas préformuladas, expressaram livremente o seu jeito de pensar e sentir de acordo com a sua própria interpretação sobre o fenômeno que vivenciaram.

Todos os participantes assinaram o termo de consentimento livre e esclarecido e trabalhamos com entrevistas semiestruturadas que tiveram a duração de 30 a 60 minutos e que foram gravadas e transcritas. Utilizamos a entrevista fenomenológica como instrumento de acesso às vivências alheias, por ser essa

\footnotetext{
2 Este estudo foi aprovado pelo Comitê de Ética em Pesquisa das Faculdades Integradas Pitágoras de Montes Claros-MG, por meio dos Pareceres Consubstanciados no 318.367 de 26/06/2013 e no 688.500 de 11 de junho de 2014, referentes à aprovação do Projeto de Pesquisa de Iniciação Científica e à aprovação do relatório final, respectivamente.
} 
uma modalidade de entrevista que possibilita a reflexão compartilhada e permite que, intersubjetivamente, a consciência do vivido se revele (Barreira \& Ranieri, 2013).

Empregamos o método fenomenológico de acordo com as orientações de Van der Leeuw (2009), visando a analisar a expressão da experiência elementar no processo de recaída vivenciado por membro de AA, a partir da elaboração da experiência dos sujeitos. $\mathrm{Na}$ primeira etapa (nomeação/classificação), tomamos cada entrevista individualmente e separamos os conjuntos que continham o mesmo significado estruturante, reunindo-os, em seguida, em unidades de significado. Essas unidades foram nomeadas, empregando-se expressões utilizadas pelos próprios participantes da pesquisa. $\mathrm{Na}$ segunda etapa (inserção do fenômeno na própria vida), procedemos na interpretação "do que se mostra" a partir da ressonância que a vivência do participante provoca no pesquisador, com consciência e método, como "signo de um sentido" a ser interpretado (p. 181).

$\mathrm{Na}$ terceira etapa (redução fenomenológica), com o fito de priorizar e clarificar as vivências sob investigação, assumimos uma atitude de epoché e, por essa via, passamos à quarta etapa: elucidação, a qual permitiu a apreensão das conexóes de sentidos comuns presentes nas entrevistas, com base na elaboração dos próprios sujeitos. A redução fenomenológica possibilitou esboçar as experiências-tipo do processo de recaída vivenciado pelos participantes. Na quinta etapa (compreensão, que toma em conjunto e, ao mesmo tempo, as etapas anteriores), buscamos aquilo que era específico das vivências experienciadas pelos participantes em seus processos de recaída e as concatenações com a expressão da experiência elementar. $\mathrm{Na}$ sexta etapa (retificação), confrontamos as experiências-tipo e a compreensão que depreendemos com os referenciais teóricos elegidos. Essa etapa possibilitou chegar à conclusão acerca da expressão da experiência elementar no processo de recaída vivenciado por membro de $\mathrm{AA}$, com base na elaboração da experiência dos sujeitos e dar o passo seguinte, a sétima etapa: reconstrução, testemunhando o que foi mostrado, pela reconstrução da experiência vivida.

\section{RESULTADOS E DISCUSSÃO}

A análise das entrevistas possibilitou a apreensão de quatro categorias temáticas: pertencimento; posicionamento pessoal; exigência de ser; e experiência religiosa. Essas categorias não foram elaboradas previamente, mas identificadas na própria análise do sentido da elaboração do sujeito, sendo que os resultados da análise de dados se encontram articulados à discussão. 


\subsection{Pertencimento}

"Todos nós somos iguais dentro de Alcoólicos Anônimos. Eu já tive essas recaídas e, as vezes que eu tive as recaídas, o pessoal do AA me aceitou bem, entendeu?" (E1)

Os membros de AA participantes desse estudo expressaram sua experiência de pertença ao grupo de AA, a partir da autodenominação de "nós" e da certeza de que "somos todos iguais". "Nós" porque partilham, no presente vivido, pelo fluxo do pensamento do outro, uma história de vida coincidente com as histórias de vida de todos os outros membros do grupo, e "iguais" porque se reconhecem na experiência de "nós", estando unidos em grupo, em busca de um objetivo comum (a sobriedade), retratando, assim, uma consciência de pertencimento.

Essa consciência de pertencimento se inicia com a responsabilidade que o sujeito toma para si de participar da construção da comunidade, na qual ele se encontra integrado, comprometendo-se com o chamado da própria comunidade (Araújo, 2013). Os membros do AA demonstram um sentimento de gratidão e de dever ao seu grupo de referência. Essa responsabilidade se traduz num cuidar de si e do outro, vez que cuidar de si, em atendimento a seus anseios fundamentais, coincide diretamente com o cuidar do outro e, assim, o membro do AA responde ao chamado de sua comunidade e, concomitantemente, ajuda na construção desta, indo à busca de sua própria realização pessoal na relação eu/mundo.

Mas a maneira de vivenciar essa relação de pertença e a forma como esta atua na comunidade e na vida pessoal de seus membros é dependente da consciência com a qual o sujeito vive essa vinculação (Araújo, 2013). Assim, a comunidade é tomada, em sua constituição, não pelo aspecto objetivo como forma social, mas pelos aspectos constitutivos que se formam a partir das experiências vividas por seus membros e que na vivência comunitária importa no reconhecimento de uma experiência de "nós" (Coelho-Junior, 2006; Coelho-Junior \& Mahfoud, 2014).

Essa experiência de "nós" reflete a partilha, na simultaneidade vivida, da experiência do fluxo da consciência do outro, a qual Schutz (2012) denominou de tese geral sobre o alter ego. Segundo essa tese, o fluxo de pensamento de uma pessoa tem a mesma estrutura fundamental que o fluxo da consciência de outra, o que importa que uma pessoa é igual a outra, na acepção de ser capaz de pensar, de agir, e que a estrutura espaçotemporal de um é equivalente à estrutura espaçotemporal do outro. Assim, uma pessoa pode experienciar tanto os atos como os pensamentos do outro, na simultaneidade vivida, e esse presente vivido, que é comum a um e ao outro, retrata a dimensão genuína do "nós", vez que 
cada um pode experienciar, reciprocamente, os pensamentos e os atos uns dos outros em sua realização vivida no presente.

Partilhando suas experiências no AA, os membros dessa comunidade constroem uma memória coletiva, que os auxiliam na recuperação, pela abstinência, ao se lembrarem, continuamente, de sua condição comum de dependentes alcoólicos (Ferreira, 2011). A memória coletiva, numa concepção halbwachiana, reporta à lembrança como reconhecimento e reconstrução, conforme o sujeito entra em contato com o sentimento daquilo que já foi visto (reconhecimento) e participa da evocação de vivências passadas em razão de interesses e preocupações presentes (reconstrução). Assim, a memória coletiva possibilita uma comparação de testemunhos (que vai oferecer maior confiança na exatidão das evocaçōes), vez que o depoimento de uma pessoa vai apoiar e dar complemento ao depoimento de outras, como se fosse iniciada uma mesma experiência e que, num conceito halbwachiano, não é mais vivenciada por apenas uma pessoa, mas por todo o grupo (Schmidt \& Mahfoud, 1993).

É a partir dessa compreensão, como se uma mesma experiência fosse vivida por várias pessoas, que estar em um grupo de $\mathrm{AA}$, compartilhando o reconhecimento e a reconstrução de suas vivências no alcoolismo, oportuniza ao membro de AA, a observação de sua experiência no processo de recaída, apoiada e complementada na experiência do outro que vivenciou semelhante processo. Nesse sentido, Stein (2005) difere as vivências individuais (que carregam um significado pessoal) das vivências comunitárias (vivências supraindividuais), vez que um sujeito, em comunidade, ao entrar em comunhão de vida com os outros membros do grupo, experienciam vivências que dizem respeito a todos eles, pois essa experiência comunitária está carregada de vivências cujo conteúdo de sentido é experimentado por todo o grupo.

Ao compartilhar suas experiências singulares no processo de recaída, num grupo de AA, o depoimento de um membro apoia e dá complemento ao depoimento dos outros membros como que iniciando uma "mesma experiência". Assim, a experiência vivida no processo de recaída favorece a observação da própria experiência, e esta auxilia na afirmação da consciência de pertença ao grupo de AA, ambas contribuindo para que o sujeito, mediante a formulação de um juízo pessoal, possa se posicionar autenticamente diante das provocaçóes da realidade. $\mathrm{E}$ ao posicionar-se autenticamente, o membro do AA está respondendo às suas exigências de ser, isto é, ele está reconhecendo a dinâmica da experiência elementar que orienta esse seu posicionamento diante de si, do outro e do mundo.

E é nesse sentido que a elaboração daquilo que o membro do AA experienciou no processo de recaída o auxilia no reconhecimento de suas exigências 
originais e oportuniza que o mesmo se posicione em concordância com aquilo que o impulsiona interiormente, isto é, a experiência elementar o auxilia no entendimento do processo de recaída, e o processo de recaída, por sua vez, explicita a dinâmica da experiência elementar.

\subsection{Posicionamento pessoal}

"Eu tentei parar de beber várias vezes, naquela ressaca brava. [...] E eu queria, é claro, largar essa vida, porque eu já tinha perdido família, perdido tudo" (E4).

Os entrevistados relatam suas dores por tentarem abandonar o seu vício e não conseguirem. Mas eles estão abstêmios há muito tempo, então, o que se pode perceber é que estão considerando que, sozinhos, não encontram a força suficiente para pararem de beber. Portanto não é que eles não conseguem se manter abstêmios, o que eles estão expressando é que se eles estão abstêmios é porque, no grupo de AA, eles encontraram o fator comunitário que agrega a força do "nós" em seus impulsos de vontade e auxilia no posicionamento pessoal (Coelho-Junior, 2006; Coelho-Junior \& Mahfoud, 2014; Stein, 1999).

Ficar diante da realidade, repensando suas atitudes de beberem excessivamente e analisá-las no confronto com as consequências advindas do alcoolismo, como a perda da família, a perda de "tudo", onde "tudo" abrange, inclusive, a perda do próprio sentido da vida, traziam aos entrevistados o incômodo que desvelava a incongruência de seus atos com seus anseios mais profundos, pois sua humanidade reclamava uma coerência com sua exigência de ser. Esse incômodo possibilitou aos participantes a observação de suas experiências, a apreensão de um significado e a emissão de um juízo: "é claro", consegue afirmar o entrevistado, que "eu queria largar essa vida”. E "é claro" porque a observação de sua experiência possibilitou clarear o entendimento de que a vida no alcoolismo não correspondia às suas exigências de ser, de felicidade, de realização.

Ao elaborar suas vivências, o ser humano consegue estabelecer relações de sentido com o mundo e emitir um juízo pessoal ao apreender o significado daquilo que experimentou (Giussani, 2009). Para emitir essa avaliação, o sujeito usa como ponto de referência o nível mais profundo de seu ser, qual seja o núcleo pessoal (Stein, 1999), que a acompanha desde sua origem e que imprime a marca da sua pessoalidade (Coelho-Junior, 2006), pois o que viabiliza "o conjunto das experiências do sujeito singular é a maneira própria com que ele absorve cada experiência" e isso porque tem, em sua estrutura humana, "um núcleo que é singular" (Cury \& Mahfoud, 2013, p. 229). Assim, o indivíduo pode decidir livremente suas ações baseando-se na motivação pessoal e concedendo uma direção singular a elas (Guimarães \& Mahfoud, 2013), vez que as tomadas 
de posição emergem dos valores captados na realidade empírica. Entretanto é necessário considerar que esses valores podem estar ou não em concordância com as direções do núcleo pessoal, visto que a realização pessoal é dependente de coerência entre as direções que o centro pessoal indica e os valores pessoais e os posicionamentos que o sujeito empreende na realidade. Assim, a falta de sintonia com o núcleo pessoal torna mais árduo ao indivíduo imprimir força para se posicionar autenticamente e, nesse sentido, Guimarães e Mahfoud (2013) expõem que o vício representa, exatamente, essa ação contrária no mundo, na qual o eu se deixa levar pelo contexto e, quanto mais é levado, mais se distancia de uma tomada de posição autêntica.

Contudo, de acordo com Stein (1999), Coelho-Junior (2006) e Coelho-Junior e Mahfoud (2014), o sujeito, ao agir, mediante um ato voluntário, pode optar por maneiras que favoreçam a coerência entre as direções do núcleo pessoal, os seus valores pessoais e o posicionamento na realidade, a partir de tomadas de posição autênticas, ao conduzir-se pela razão e pelos impulsos da vontade na repressão dos impulsos psíquicos. Portanto, por meio de um ato voluntário, o sujeito pode transformar um querer em um fazer, pela mobilização da energia necessária para realizar determinada ação, podendo resistir tanto aos obstáculos internos quanto aos externos que se apresentem como dificultadores da ação. Note-se que é o querer que proporcionará o impulso imprescindível para essa ação, vez que é introduzido pelos motivos que vão lhe oferecer a energia necessária para que se possa transformar o querer em fazer.

Não estava trabalhando mais, [...] eu comecei a ter que vender as coisas. Eu tinha uma carpintaria, lá, montada, eu vendi as máquinas, fui vendendo e bebendo. E teve uma hora que eu cheguei entre a cruz e a espada. [...] Não tinha outro caminho para mim (E4).

Os participantes deixam emergir, ao contar suas experiências vividas no processo de recaída, a não correspondência de suas atitudes com seus anseios fundantes, o que possibilita respostas não razoáveis (Giussani, 2009) como ir "vendendo e bebendo" as máquinas que representam o seu sustento, ao ponto de se situar em um lugar denominado "entre a cruz e a espada", lugar indicativo de que o entrevistado deveria fazer uma difícil escolha, que lhe soava mais como uma imposição, pois não "havia outro caminho" para ele. Essa imposição é recebida, pelo participante, como um imperativo da consciência, solicitando urgência de um posicionamento, no sentido de "dever ser", em sua existência, algo diferente do que ele estava sendo. Ao afirmar que não havia outro caminho, o participante fala a partir de seus valores individuais, que ele deveria "vir a ser" o que ele ainda "não era". Essa urgência de posicionamento revela-se por meio da consciência moral, de maneira fundamentalmente intuitiva (Frankl, 2011a). 
Os membros do AA admitem ser impotentes perante o álcool e, ao mesmo tempo, responsabilizam-se por sua recuperação, manejando recursos pessoais e impulsos da vontade para resistir às dificuldades que se apresentam em sua realidade. Nesse sentido, os entrevistados têm consciência da imprescindibilidade de seus posicionamentos pessoais para manterem-se abstêmios e alcançarem a sobriedade.

"Me despertou que eu precisava fazer uma recuperação, mudar o meu jeito de ser, na morte de um familiar meu" (E2).

Relatando suas experiências no alcoolismo e, particularmente, no processo de recaída, os participantes identificam experiências que os tocaram tão profundamente, que mobilizaram uma força de vontade interna que possibilite que eles elaborem suas experiências e emitam um juízo a respeito do que eles estavam fazendo de suas vidas. Isso que os entrevistados expressam diz respeito à dimensão especificamente humana, que sempre faculta à pessoa converter o sofrimento num triunfo, extraindo do sentimento de culpa a oportunidade de transformar a si próprio para melhor (Frankl, 2012).

Entretanto, para posicionar-se, é necessário que o sujeito seja capaz de afirmar o que ele discerne como fundamental para ele, de maneira que nada seja impedimento para que caminhe em direção àquilo que mais lhe corresponda (Giussani, 2009; Mahfoud, 2012). Os entrevistados são unânimes em relatar que o convívio com os membros do AA facilita o enfrentamento das dificuldades trazidas pela abstinência, aumentando a motivação para continuarem abstêmios. Essa necessidade de estar em um grupo de AA, que eles enfatizam, exprime-se no reconhecimento de que o fator comunitário oportuniza o retorno ao centro pessoal de uma maneira que não acontece quando a pessoa, sozinha, decide dar um direcionamento à sua experiência (Mahfoud, 2012).

\subsection{Exigências de ser}

Se eu voltar a beber, eu vou destruir tudo que eu estou conseguindo construir (E1).

Por essa narrativa, pode-se perceber que o fato de o entrevistado estar abstêmio não retira dele a busca contínua por respostas e significados para as suas perguntas fundamentais. É a adesão à realidade que oportuniza que os membros do AA continuem fazendo experiência de correspondência a seus anseios mais profundos, possibilitando o posicionamento autêntico. Então não é questão de apenas parar de beber, mas de pôr em ação uma dinâmica interna que transcenda à mera ressonância afetiva e responda às suas exigências de ser, dando significado à própria vida. 
Giussani (2009), considerando as características essenciais da experiência humana, apresenta o conceito de experiência elementar, como ponto referencial do sujeito, que tem critérios imanentes, pelos quais uma pessoa pode comparar e avaliar todas as suas experiências com as suas exigências e evidências originais. Essas exigências, explica Giussani (2009), são "como uma centelha que põe em ação o motor humano" e, assim, "qualquer afirmação de uma pessoa, desde a mais banal e cotidiana à mais ponderada e plena de consequências, só pode ser feita tendo por base esse núcleo de evidências e exigências originais" (p. 25). E Mahfoud (2012) expõe que não há nada mais original no ser humano do que a exigência de ser, vez que tudo nele exprime essa exigência e "todo dinamismo da experiência elementar é nossa exigência de ser em ato" (p. 55). E é exigência de ser em ato, porque, para ser, a pessoa depende, pois o sentido da existência de uma pessoa depende de que ela seja presença para alguém, que deixe, portanto, a marca da sua pessoalidade no mundo.

Teve uma época que eu tive uma recaída, eu cheguei aqui quase no horário da reunião e eu tinha bebido. Mas eu vim para cá porque estava na rua desesperado. Eu ia continuar bebendo. Mas eu falei: "Meu Deus, eu bebi, eu não devia ter bebido, mas mesmo assim eu vou para o AA". [...] fiquei quieto durante a reunião toda, mas já no outro domingo eu estava frequentando a reunião normalmente (E1).

Elaborar sua experiência de recaída possibilita ao participante dizer "eu bebi", mas "eu não devia ter bebido", o que viabiliza que ele reconheça que o alcoolismo não é coerente ao que ele deseja para a própria vida e, por isso, ele se desespera. E no desespero porque ele "ia continuar bebendo", no sofrimento pela possibilidade de continuar fazendo o mal a si próprio, o propósito da vida se revela, pois, em sua dor, ele reconhece o desejo de um bem pelo qual ele espera existencialmente. Mahfoud (2012) explica que, ainda que a pessoa não saiba discernir claramente o que ela espera, ela tem a "experiência de que não" lhe "serve qualquer coisa" porque ela pode "comparar aquilo que está acontecendo com uma espera e, por meio dela", consegue afirmar "isso tem a ver comigo, isso não tem a ver comigo" (p. 232).

No tensionamento entre o reconhecimento de suas exigências originais e a experiencia de recaída vivenciada pelo participante, há um posicionamento deste que evidencia a espera de um bem: "mesmo assim eu vou para o AA". Ele vai para o AA "mesmo assim", porque o participante reconhece a valorização da vida presente em sua experiência e identifica que a decisão e a tomada de posição para não beber são dele. $O$ reconhecimento de sua exigência de bem oportuniza uma mudança na dinâmica interna do participante diante da recaída e, "já no outro domingo", ele "estava frequentando a reunião normalmente". O significado expresso em "normalmente" diz do acolhimento da vontade de não beber em razão do reconhecimento de uma exigência fundamental. 
"Tinham quantas pessoas ao meu redor que me ajudavam daqui, dali. [...] Como é que não iriam ficar essas pessoas depois que eu ingerisse o primeiro gole? Quem ia sofrer?" (E3)

Recair significaria voltar a fazer mal a si e ao outro e, portanto, distanciar-se de sua exigência de bem. Pela elaboração de sua experiência, no processo de recaída, o entrevistado consegue ficar diante da pergunta: a quem eu farei sofrer se eu recidivar? Assim, deixar de fazer uso de bebidas alcoólicas tem significado para o entrevistado não somente no sentido de cuidar de si, mas também no sentido de favorecer a felicidade do outro. Quando o sujeito sintoniza com o próprio eu, ele abre a possibilidade para sintonizar também com o outro, vez que a exigência de ser é uma exigência de existir de maneira significativa para o outro. Nesse sentido, quando o sujeito decide cuidar de si, buscando a sua própria realização, essa busca coincide "com o favorecimento da felicidade alheia" (Guimarães \& Mahfoud, 2013, p. 199).

Em suas análises acerca do pensamento antropológico e ético em Paul Ricoeur, Tavares (2006) explica que, se o mal se manifesta pelos atos do ser humano, o mesmo pode ser entendido como obra da liberdade e responsabilidade humanas e que, portanto, "está nas mãos do homem a possibilidade de o evitar" (p. 142). E porque o ser humano é exigência de bem, Mahfoud (2012) assevera que o mal é "a contradição que se insere na nossa exigência de bem, um passo em falso vivido num gesto constituído pela exigência de ser", e essa dor que emerge quando o homem realiza o mal aparece como expressão da própria exigência de bem (p. 58).

\subsection{Experiência religiosa}

"É difícil a pessoa largar um vício [...]. E depois que a gente larga, eu acho que a gente tem que apegar muito com Deus e pedir, primeiramente, Ele, porque sem Ele a gente não é nada, né?" (E5)

Nos grupos de AA, ninguém é induzido a confessar-se crente a um Deus, mas eles nutrem a crença em um Poder superior a eles, que os auxilia a não recair. Entretanto cada membro vivencia sua experiência espiritual de maneira individualizada e em conformidade com a concepção que cada um tem de Deus. Todos os participantes dessa pesquisa fizeram menção à forte crença de que eles permanecem abstêmios porque Deus lhes dá a força interior necessária para assim continuarem, o que não quer dizer, em absoluto, que eles traduzem sua experiência religiosa por uma "fé cega", já que consideram a necessidade da vontade deles como imperativo para evitarem a recaída. 
Giussani (2009) afirma que, ao ficar diante da realidade, o sujeito se irrompe na busca por respostas às perguntas despertadas pelos próprios acontecimentos da vida: "Qual é o significado último da existência?" e "De que e para que é feita a realidade?” (p. 73). Essas perguntas, entretanto, só podem ser respondidas se avaliadas numa dimensão de correspondência total a uma alteridade infinita, visto que as respostas estão para além da pessoa, que as endereça a Outro acima de si mesmo, pois provoca, no sujeito, um despertar de "uma voz" que soa como atrativo para um sentido que está acima dele. Essa dimensão, nomeada de senso religioso, "é a capacidade que a razão tem de exprimir a própria natureza profunda na interrogação última", sendo que referida interrogação "está em cada indivíduo e dentro do seu olhar para todas as coisas", pois representa "o lócus da consciência que o homem tem da existência” (p. 88, grifos do autor).

O senso religioso também é identificado como dimensão constituinte da pessoa por Stein (1983), como capacidade estrutural desta, que possibilita a apreensão do sentido da realidade e reconhecimento do Mistério nela presente. E identificar o senso religioso na estrutura da pessoa, explicam Coelho-Junior e Mahfoud (2013), "possibilita reconhecer esta disponibilidade estrutural para o conhecimento da presença do Mistério", por meio da própria realidade, "que passa a ser sinal de Sua presença” (p. 268). Dessa maneira, o senso religioso viabiliza a passagem para a vivência de uma experiência religiosa e, no percurso da busca do sentido da vida, a experiência religiosa mostra-se de fundamental importância, vez que a autotranscendência da existência, característica ontológica fundamental humana, expressa a vontade de sentido, que é o interesse que prepondera no ser humano. Este interesse se direciona para alguma coisa ou para algo diverso dele mesmo, no mundo externo, e busca, nesse mundo, um sentido a realizar, uma pessoa a quem amar ou uma causa à qual se dedicar e, por intermédio dessa via, o homem responde às provocaçóes da vida (Frankl, 2010, 2011a, 2011b). Trata-se, portanto, conforme aponta Mahfoud (2012), de "reconhecer a valorização da vida que está presente sempre nas experiências", pois a questão é de reconhecimento de uma exigência mais original, direcionada pela experiência elementar e que muda "a dinâmica do sujeito diante de sua vida" (p. 71), e por isso os entrevistados afirmam que eles têm de "apegar muito com Deus e pedir, primeiramente, Ele, porque sem Ele a gente não é nada”.

\section{CONSIDERAÇÕES FINAIS}

O programa terapêutico do AA possibilita a recuperação do alcoolista, quando este, por um posicionamento pessoal, decide pela abstinência do álcool, uma vez que, como em qualquer escolha livre que se faça, a manifestação da 
vontade pessoal torna-se imprescindível. Ao partilharem suas experiências na comunidade de AA, seus membros tendem a desenvolver a percepção de que a recaída, apesar de evitada, uma vez ocorrida, pode ser utilizada a favor do próprio membro que a experienciou, quando este se apropria dos sentidos que o processo de recaída teve para ele. Evidencia-se, entretanto, que essa elaboração é, em geral, anterior ao ingresso dos alcoolistas num grupo de AA e que, uma vez decididos pela abstinência, essas pessoas buscam, no convívio com o AA, a manutenção da sobriedade. Tendo outras experiências de recaída, já ingressados no grupo, o alcoolista encontra o apoio dos outros membros, o que viabiliza um retorno mais eficaz e consciente à reabilitação.

A experiência de comunidade no AA não se detém em seus aspectos objetivos e institucionais, mas antes se enraíza nas vivências comuns que se realizam no encontro com outro membro e que mobilizam a dinâmica interna do alcoolista, possibilitando a elaboração de sentido e provocando novas tomadas de posições pessoais. Portanto o encontro com o outro membro de AA não se encerra apenas no fato de os membros seguirem determinado programa terapêutico. Ao contrário, esse encontro, que implica trocas empáticas, é que vai oportunizar uma abertura a um horizonte mais amplo, favorecida a partir do reconhecimento recíproco das vivências comuns e da ampliação do conhecimento de si próprio que mobilizam a dimensão da liberdade e responsabilidades humanas.

A dinâmica da experiência elementar evidenciou-se nos três momentos do processo de recaída vivido pelos participantes deste estudo. Ao narrarem os momentos em que, ainda bebendo, dispuseram-se a parar de beber, diziam-se certos de que o alcoolismo não correspondia àquilo que eles realmente ansiavam para vida, pois eles esperavam por algo que não podia ser qualquer coisa. Ao contarem de sua recaída no alcoolismo, diziam da dor, da experiência de culpa e do sentimento de fracasso que os invadia porque eles agiam de maneira que não correspondia àquilo que eles esperavam. E, ao falarem sobre a vivência de se manterem sóbrios, verificamos a expressão da experiência elementar vivida por eles em seus processos de recaída, da paz e do maravilhamento de poderem dizer "Graças a Deus!", pois eles sentiam que a vivência da sobriedade tinha a ver com eles e, por isso mesmo, eles escolheram a direção apontada por suas exigências originais e decidiram-se viver sóbrios.

A experiência elementar, evidenciada no próprio reconhecimento das exigências fundamentais humanas, permite considerar não apenas o enfrentamento do sofrimento, mas da própria vida, oportunizando posicionamentos existenciais. Portanto a relação do alcoolista com a bebida perpassa pelo reconhecimento de um critério que explicita um juízo, pois é a própria experiência de não correspondência às suas exigências fundamentais que direciona o alcoolista a 
considerar que há algo para ser revisto em sua existência. Apostar nesse dinamismo evidencia que continuar bebendo exageradamente é uma opção rasa demais para dar conta do sentido que o alcoolista busca em sua existência. Assim, a exigência que se apresenta no momento da recaída desperta o alcoolista para um horizonte de totalidade e de realização que ele sozinho não conseguiria construir. E o senso religioso emerge não como um fator terapêutico, mas como uma experiência autêntica percebida como o despertar de "uma voz" que soa como atrativo para um sentido que alimenta a sua vontade de continuar sóbrio. 


\section{REFERÊNCIAS}

Alcoólicos Anônimos. (2008). Alcoólicos Anônimos (4a ed.). São Paulo: Junaab.

Alcoólicos Anônimos. (2011). Os doze passos e as doze tradiçôes. São Paulo: Junaab.

Araújo, R.A. (2013). Uma tradição viva, raízes para a alma: análise fenomenológica de experiências de pertencer em uma comunidade rural de Minas Gerais. In M. Mahfoud \& M. Massimi (Orgs.), Edith Stein e a Psicologia: teoria e pesquisa. (pp. 359-380). Belo Horizonte: Artesã.

Álvarez, A. M. A. (2007). Fatores de risco que favorecem a recaída no alcoolismo. Jornal Brasileiro de Psiquiatria, 56(3), 188-193. Recuperado a partir de http:// www.scielo.br/pdf/jbpsiq/v56n3/a06v56n3.pdf

Barreira, C. R. A. \& Ranieri, L. P. (2013). Aplicação de contribuições de Edith Stein à sistematização de pesquisa fenomenológica em Psicologia: a entrevista como fonte de acesso às vivências. In M. Mahfoud \& M. Massimi (Orgs.), Edith Stein e a Psicologia: teoria e pesquisa. (pp. 449-466). Belo Horizonte: Artesã.

Coelho-Junior, A. G. (2006). As especificidades da comunidade religiosa: pessoa e comunidade na obra de Edith Stein. (Dissertação de Mestrado), Universidade Federal de Minas Gerais, Belo Horizonte.

Coelho-Junior, A. G. \& Mahfoud, M. (2013). As especificidades da comunidade religiosa na obra de Edith Stein. In M. Mahfoud \& M. Massimi (Orgs.), Edith Stein e a Psicologia: teoria e pesquisa. (pp. 263-292). Belo Horizonte: Artesã.

Coelho-Junior, A. G. \& Mahfoud, M. (2014). Vontade e experiência comunitária à luz de Edith Stein. In G. L. Santos \& M. R. Farias (Orgs.), Edith Stein: a pessoa na Filosofia e nas Ciências Humanas. (pp.243-258). São Paulo: Fonte.

Conselho Federal de Psicologia. (2013). Referências técnicas para a atuação de psicólogaslos em políticas públicas de álcool e outras drogas. Brasília: CFP. Recuperado a partir de http://crepop.pol.org.br/novo/wp-content/ uploads/2013/12/CREPOP_REFERENCIAS_ALCOOL_E_DROGAS_ FINAL_10.01.131.pdf

Cury, B. T. \& Mahfoud, M. (2013). Núcleo pessoal e liberdade na formação da pessoa a partir de Edith Stein. In M. Mahfoud \& M. Massimi (Orgs.), Edith Stein e a Psicologia: Teoria e pesquisa. (pp. 217-237). Belo Horizonte: Artesã. 
Ferreira, L. O. (2011). Nosso remédio é a palavra: uma etnografia sobre o modelo terapêutico de alcoólicos anônimos. Cadernos de Saúde Pública, 27(1), 195-198. Recuperado a partir de http://www.scielo.br/scielo.php?script=sci_ arttext\&pid=S0102-311X2011000100022\&lng=en\&nrm=iso

França, M. G. \& Siqueira, M. M. (2011). O papel da Enfermagem e a formação de multiplicadores ante o processo de prevenção à recaída. Revista Eletrônica Saúde Mental, Álcool e Drogas, 7(2), 78-84.

Frankl, E. V. (2012). Em busca de um sentido: um psicólogo no campo de concentração (32 Aufl., rev., W. O. Schlupp \& C. C. Aveline, Trad.). São Leopoldo: Sinodal; Petrópolis: Vozes.

Frankl, E. V. (2010). Psicoterapia e sentido da vida: fundamento da logoterapia e análise existencial. (5 Aufl., A. M. de Castro (Trad.). São Paulo: Quadrante.

Frankl, E. V. (2011a). A presença ignorada de Deus. (13 Aufl., rev., W. O. Schlupp \& H. H. Reinhold, Trad.). São Leopoldo: Sinodal; Petrópolis: Vozes.

Frankl, E. V. (2011b). A vontade sentido: fundamentos e aplicaçôes da logoterapia (I. S. Pereira, Trad.). São Paulo: Paulus.

Gaspar, Y. E. \& Mahfoud, M. (2006, Junho). Uma leitura histórica do conceito de experiência e uma proposta de compreensão do ser humano em seu caráter essencial: experiência elementar e suas implicaçôes para a Psicologia. In Anais, 3 Sipeq \& 5 Efae. São Bernardo do Campo: SP\&EQ; UMESP.

Gil, A. C. (2008). Métodos e técnicas de pesquisa social (6a ed.). São Paulo: Atlas.

Giussani, L. (2009). O senso religioso. (P. A. E. Oliveira, Trad.). Brasília: Universa.

Guimarães, A. C. B. \& Mahfoud, M. (2013). Tornar-se si mesmo: elaborações a partir de Luigi Giussani e Edith Stein. In M. Mahfoud \& M. Massimi (Orgs.), Edith Stein e a Psicologia: teoria e pesquisa. (pp. 195-216). Belo Horizonte: Artesã.

Mahfoud, M. (2012). Experiência elementar em Psicologia: aprendendo a reconhecer. Brasília: Universa; Belo Horizonte: Artesão.

Passos, E. H. \& Souza, T. P. (2011). Redução de danos e saúde pública: construçõos alternativas à política global de "guerra às drogas". Psicologia \& Sociedade, 23 (1), 154-162. Recuperado a partir de http://www.scielo.br/pdf/ psoc/v23n1/a17v23n1.pdf 
Pires, F. B. \& Schneider, D. R. (2013). Projetos de vida e recaídas em pacientes alcoolistas. Arquivos Brasileiros de Psicologia, 65(1), 21-37. Recuperado a partir de http://pepsic.bvsalud.org/scielo.php?pid=S180952672013000100003\&script=sci_arttext

Rigotto, S. D. \& Gomes, W. B. (2002). Contextos de abstinência e de recaída na recuperação da dependência química. Psicologia: Teoria e Pesquisa, 18(1), 95106. Recuperado a partir de http://www.scielo.br/pdf/ptp/v18n1/a11v18n1. pdf

Schmidt, M. L. S. \& Mahfoud, M. (1993). Halbwachs: memória coletiva e experiência. Psicologia USP, 4(1-2), 285-298.

Schutz, A. (2012). Sobre fenomenologia e relaçōes sociais. (R. Weiss, Trad. \& H. T. R. Wagner, Org.). Petrópolis: Vozes.

Stein, E. (2005). Contribuiciones a la fundamentación filosófica de la Psicología y de las ciencias del espíritu. In E. Stein, Obras completas: escritos filosóficos (etapa fenomenológica: 1915-1920). F. J. Sancho e cols., (Trad.), (Vol. 2, pp. 254-273). Burgos: Monte Carmelo.

Stein, E. (1999). Psicologia e scienze dello spirito: contributi per uma fondazione filosófica. A. M. Pezzella (Trad.). Roma: Città Nuova.

Stein, E. (1983). Vie della conoscenza di Dio. In E. Stein. Vie della conoscenza di Dio. G. della Croce, o.c.d., Trad., pp. 125-187). Padova: Messaggero.

Tavares, M. (2006). Fundamentos metodológicos do pensamento antropológico e ético de Paul Ricoeur: o problema do mal. Memorandum, 10, 136-146.

Van der Leeuw, G. (2009). A religião em sua essência e suas manifestações: Fenomenologia da religião, epílogo. Revista Abordagem Gestalt, 15 (2), 179183. 